\title{
Cracks Monitoring and Resistivity Test for a Double-Storey House due to Cavity in the Soil
}

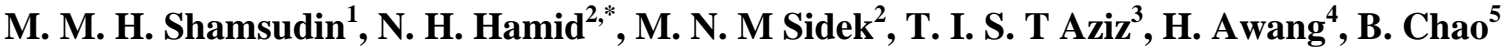 \\ ${ }^{1}$ School of Civil Engineering, College of Engineering, Universiti Teknologi MARA, 40450 Shah Alam, Malaysia \\ ${ }^{2}$ Institute for Infrastructure Engineering and Sustainable Management (IIESM), Engineering Complex, Universiti Teknologi MARA, \\ 40450 Shah Alam, Malaysia \\ ${ }^{3}$ Department of Architecture, Faculty of Built Environment and Surveying, Universiti Teknologi Malaysia, 81310 Skudai, Johor, \\ Malaysia \\ ${ }^{4}$ Department of Civil Engineering, College of Engineering, Universiti Malaysia Pahang, Campus Gambang, Lebuhraya Tun Razak, \\ 26300, Gambang, Kuantan, Malaysia \\ ${ }^{5}$ School of Civil Engineering and Hydraulic Engineering, Ningxia University, Yinchuan, China
}

Received May 4, 2021; Revised June 22, 2021; Accepted July 19, 2021

\section{Cite This Paper in the following Citation Styles}

(a): [1] M. M. H. Shamsudin1, N. H. Hamid, M. N. M Sidek, T. I. S. T Aziz, H. Awang, B. Chao , "Cracks Monitoring and Resistivity Test for a Double-Storey House due to Cavity in the Soil," Civil Engineering and Architecture, Vol. 9, No. 5, pp. 1376 - 1388, 2021. DOI: 10.13189/cea.2021.090511.

(b): M. M. H. Shamsudin, N. H. Hamid, M. N. M Sidek, T. I. S. T Aziz, H. Awang, B. Chao (2021). Cracks Monitoring and Resistivity Test for a Double-Storey House due to Cavity in the Soil. Civil Engineering and Architecture, 9(5), 1376 - 1388. DOI: 10.13189/cea.2021.090511.

Copyright $\odot 2021$ by authors, all rights reserved. Authors agree that this article remains permanently open access under the terms of the Creative Commons Attribution License 4.0 International License

\begin{abstract}
This paper presents the feasibility study of structural assessment and monitoring of two-story house due to soil settlement which was not well-compact before construction commenced. Two stages assessments were conducted to monitor and evaluate the structural integrity of existing double-story house which involves preliminary investigation and detailed assessment. Preliminary investigation includes visual inspection of cracks, soil settlement and structural damages. Meanwhile, detailed assessment comprises of crack width measurement, Non-Destructive Test (NDT) and resistivity test. The first detail assessment was carried out on 18th July 2019 which involved crack width measurement, Ultrasonic Pulse Velocity (UPV) test and rebound hammer test. The second inspection was conducted on 19th October 2019 to monitor and identify the integrity of the structure and the main causes of the problem. Visual inspection and non-destructive test indicate that the defects found in the house can be categorized as partial damage due to soil settlement. Resistivity test showed that there were cavities and void areas underneath the house and during raining season these void areas were filled with water. The soil underneath the house consists of clay, sand, alluvium and limestone. Results from rebound hammer and Ultrasonic
\end{abstract}

Pulse Velocity (UPV) during the monitoring works showed that low compressive strength and poor quality of concrete were developed, respectively. Besides that, monitoring crack width using veneer caliper showed that the crack was active and extended in a short period of time. Therefore, it is recommended to fill up the void area underneath the house with self-compacting concrete in order to control the cracks and structural damages of double-story house.

Keywords Non-destructive Test, Rebound Hammer, Ultrasonic Pulse Velocity, Soil Settlement, Structural Integrity

\section{Introduction}

Forensic engineering is defined as the application of engineering principles or judgment of failures to infrastructures and buildings through monitoring and assessment for certain period of time. It has grown substantially in recent years as consumers have demanded ever-increasing levels of quality and maintenance. Moreover, forensic engineering also involves an 
investigation work on structures, materials, component products, cause of failure or does not operate/function as designed, leading to the effect of personal injury, damage to property and economic loss [1]. Structural Health Monitoring (SHM) is one of the methods in forensic engineering to monitor the structural damages using vibration method in Non Destructive Test (NDT). By alteration of dynamic properties of structures such as structural response, frequencies, mode shapes, damping and modal strain energy could be used to monitor the structural damages with respect of time [2]. Structural damages of buildings are occurred due to earthquakes, landslides, soil settlements, floods and other natural disasters. The structural damages due to earthquakes can be simulated and observed through experimental work in the laboratory. For example, the cracks and damages for three types of beam-column joint under vertical and in-plane lateral cyclic loading can be classified according to color coding, description of damage level, displacement, drift and ductility $[3,4,5]$. Based on these experimental works, moderate to minor damages of structures can be repaired, retrofitted and monitored the cracks propagation in the Heavy Structure Laboratory, Universiti Teknologi Mara, Selangor, Malaysia [6].

However, the structural damages and cracks of buildings cannot be monitored closely as in the laboratory due to locations and accessibility to the site. Most of the cracks in buildings were found to be caused by the settlement of the building due to the nature of the predominant soil type found within the area [7]. The principal causes of occurrence of cracks in buildings are due to moisture changes, thermal variations, elastic deformation, creep, chemical action, foundation movement and settlement of soil and vegetation [8]. A case study on structural damages on the walls and floors of semi-detached resident houses was due to soil settlement rather than the initial assumption that caused the cracking was due to piling work at nearby construction works [9]. The change in groundwater conditions, moisture contents and soil differential settlement can cause the structural failures of the buildings [10]. The groundwater level is influenced by rainfall intensity and pore water pressure which cause the slope stability and resulting cracks of building within the vicinity [11]. During raining season, the cavities in the soil will be filled by water and these cavities can be determined by conducting resistivity test. The voids or cavities in the ground can result in potentially dangerous collapse of roads or cracks of buildings $[12,13]$. Cement-based grout is recommended to be injected into the subsurface cavities to improve the strength of subsurface materials and reduce permeability after conducting electrical resistivity surveys [14]. Therefore, it is recommended that electrical resistivity surveys can be applied in solving selected geotechnical problems at site and environmental problems
[15].

The main purpose of this study is to predetermine the actual cause of the structural damages for double-story house before the actual repairing work takes place. The inspection and investigation were conducted on a two-story terrace house after suffering severe damages and falling of concrete from the wall. It consists of car porch, living room, dining room, three bedrooms, three bathrooms, two stores, staircase, hallway and kitchen. The inspection was carried out around this area has pre-assumed that path of water flow due to soil settlement and the movement of underground water beneath the house was expected to be the main cause of cracks. The neighboring houses also experienced similar defects and the cracks were developed at floor tiles of the ground floor area. Therefore, the NDT test such as Ultrasonic Pulse Velocity (UPV), measurement crack width using Vernier Caliper, rebound hammer test and electrical resistivity test were to be carried out to monitor the cracks propagation and cause of cracks in double-story residential house due to soil settlement.

\section{Stages of Conditional and Test Methods}

The inspection has been thoroughly conducted around the house as well as at every level. The main focus of this visual inspection is to observe and identify the types of cracks and its severity which was found in columns, beams, floors and walls. Cracks on the surface of the concrete structure are major indicators of damage and deficiencies in the strength of the concrete structure. Cracks can be categorized into two major areas which are Structural Cracks and Non-Structural Cracks [16]. Immediate actions and rehabilitations are required if the Structural Cracks Category are major which can cause damage to the entire structure of the building, while the Non-Structural Cracks Category will not involve structural failure of the building but will impair its architectural superiority. Table 1 shows the category and classification of cracks width based on previous researchers' work [7,17]. This table will be used to categorize the cracks width for double-story house in this study after visual observation and inspection.

Table 1. Category and classification of cracks width $[7,17]$

\begin{tabular}{|c|c|c|c|}
\hline $\begin{array}{c}\text { Crack Width } \\
\text { (mm) }\end{array}$ & Class & Classification & Category \\
\hline Less than $2 \mathrm{~mm}$ & Very Slight & Aesthetic & 1 \\
\hline $2 \mathrm{~mm}$ to $5 \mathrm{~mm}$ & Slight & Aesthetic & 2 \\
\hline $5 \mathrm{~mm}$ to $15 \mathrm{~mm}$ & Moderate & Serviceability & 3 \\
\hline $15 \mathrm{~mm}$ to $25 \mathrm{~mm}$ & Severe & Serviceability & 4 \\
\hline Over $25 \mathrm{~mm}$ & Very Severe & Stability & 5 \\
\hline
\end{tabular}


This study is proposed to assess and monitor the structural health monitoring and soil properties of a two-story house that consists of two main stages which are preliminary and detailed assessment. On-site testing works have been conducted appropriately with a suitable research methodology and equipment to examine the severity of existing structure and non-structure damage, also the causes of the damage. The structural integrity of the house was examined through crack width measurement and NDT while the soil profiles were evaluated using resistivity test. The type of equipment used and the methods followed for conducting the tests in order to fulfill the objectives of this study are well-explained as follows under preliminary investigation and detailed investigation.

\section{Preliminary Investigation}

This stage involves visual inspection, meeting and review of data records. All available documents were examined which include technical specifications, past reports of tests or inspection made, layout plan of the house, construction records, details of materials used, methods and dates of construction. During visual inspection, all defects were identified, the degree of damages was classified and causes of damages were also identified. Visual comparison of similar members is particularly valuable as a preliminary to testing to determine the extent of the problems in such cases.

\section{Detailed Investigation}

After preliminary investigation on double-storey house was conducted on July 2017 and the engineering judgment was concluded on this building has undergone several minor to severe cracks. A detailed investigation was conducted in two stages which are on $18^{\text {th }}$ of July 2019 and $19^{\text {th }}$ of October 2019 in order to identify the severity of the structural damages of this house. The NDT tests are crack width measurement, Ultrasonic Pulse Velocity (UPV) test is to determine concrete quality and Rebound hammer test is to determine the compressive strength of concrete. Resistivity test was conducted on $23^{\text {th }}$ of July 2019 inside the house to determine the soil profile underneath the house.

\section{Cracks Measurement}

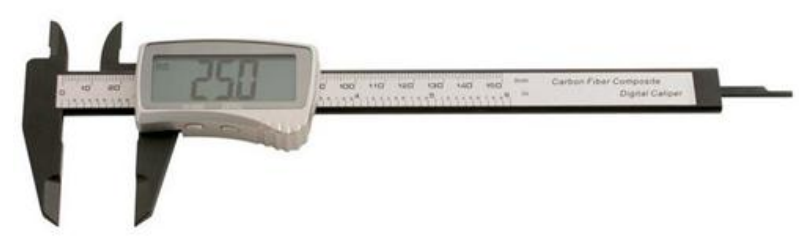

Figure 1. Calibrated Vernier Caliper
The cracks width on the walls and floors were measured using calibrated Vernier caliper as shown in Figure 1. Crack width was measured at the locations that have crack markings on the walls, along the beam and column of the house.

\section{Non Destructive Test (NDT)}

Ultrasonic Pulse Velocity (UPV) test was conducted according to BS EN 12504-4:2004 and applied on all visible crack lines or opening around the building to ensure the presence of discontinuities within concrete structure to describe quality of concrete. UPV testing is used to determine the integrity of structural concrete by measuring the speed and attenuation of an ultrasonic wave passing along a specific test path in the element being tested. The test was examined on visible cracks occurred to ensure the existence of depth in crack within the structure. Figure 2 shows the complete set of UPV equipment. Before measuring the pulse velocity using the transducers, a thin layer of grease was applied to the testing members acting as acoustic coupling between the transducers and concrete surface. This study was applied $200 \mathrm{~mm}$ and $300 \mathrm{~mm}$ path length for pulse travel in in order to measure the UPV value. The ultrasonic pulse velocity value was calculated using UPV equation that equals to path length over time travel.

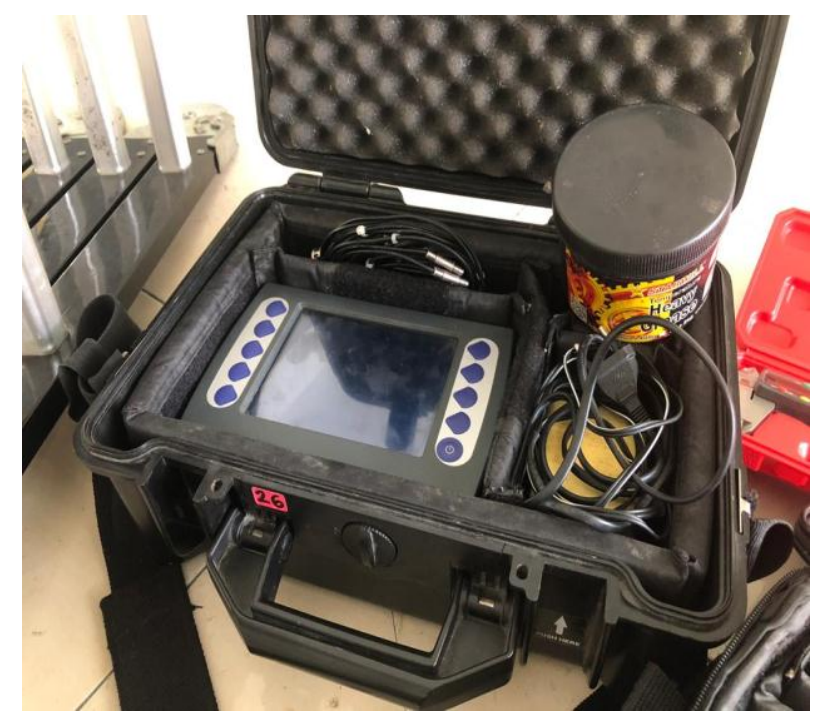

Figure 2. Ultrasonic Pulse Velocity Equipment

The Schmidt rebound hammer test was carried out at several locations of damages structure that experience distress following BS EN 12504-2:2001 to determine the existing compressive strength of the concrete. For testing purposes, smooth, clean and dry surface were selected and if any loosely adhering scale was present, this was rubbed off with a grinding wheel or stone. Rough surfaces resulting from incomplete compaction, loss of grout, spalled or tooled surfaces do not give reliable results and 
should be avoided. The average of nine readings of rebound hammer per location was tested in order to obtain an accurate reading. The Schmidt rebound hammer equipment is as shown in Figure 3.

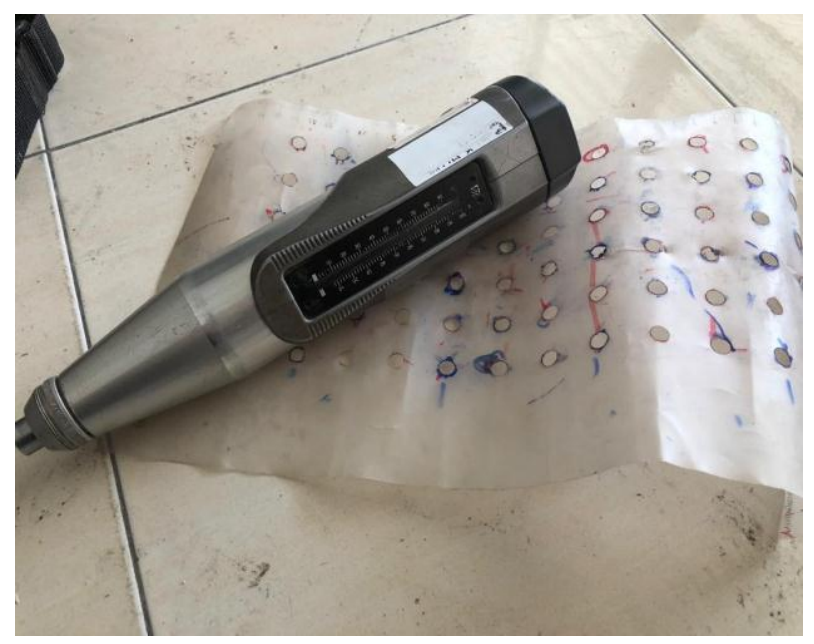

Figure 3. Rebound Hammer Equipment

\section{Method for Resistivity Test}

Soil resistivity test was conducted to measure the resistance of soil or to resist electric current. The data is used to make sub-surface geophysical surveys as an aid in identifying ore location, depth of bedrock and other geological phenomena. Figure 4 shows the ABEM Terrameter LS2 and Lund electrode selector ES10-64 which were used for resistivity test and to investigate the properties of soil at the case study location. Resistivity test was conducted using one line inside the house and one line in front of the house. For data collection, 41 electrodes were arranged in a straight line with constant spacing of $5 \mathrm{~m}$ and connected to a $200 \mathrm{~m}$ multi-purpose cable. In data acquisition, there are various types of array that suitable to be applied which depends on several factors. The array configuration has a substantial influence on the resolution, sensitivity and depth of investigation. Figure 5 shows the arrangement of ABEM Terrameter LS2 with other equipment such as multi-purpose cable, jumper cable, steel electrode and one unit 12 volt battery. ABEM S4KWin 3.32 software is used to transfer the raw data from Terrameter and convert it into a standardized format readable by Res2DINV. The least-squares inversion method of Res2DINV software is used in geoelectrical resistivity data processing in this study.

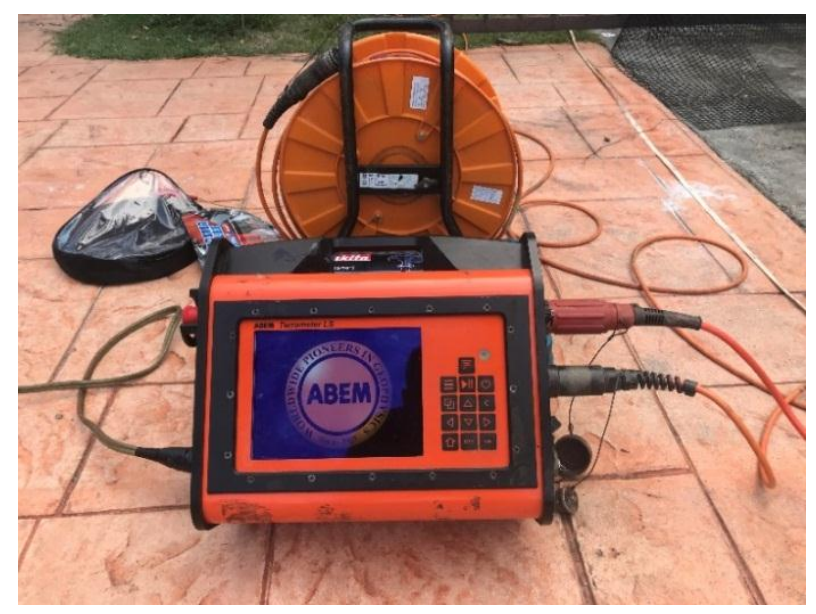

Figure 4. ABEM Terrameter LS2 and 200m cable

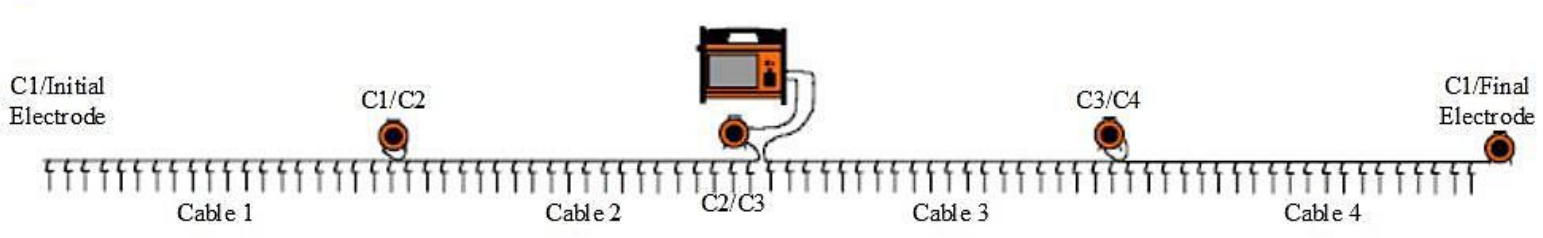

Figure 5. Systematic arrangement of ABEM Terrameter LS2 with other equipment [23]. 


\section{Analysis and Interpretation of Site Results}

\subsection{Visual Observation of Cracks}

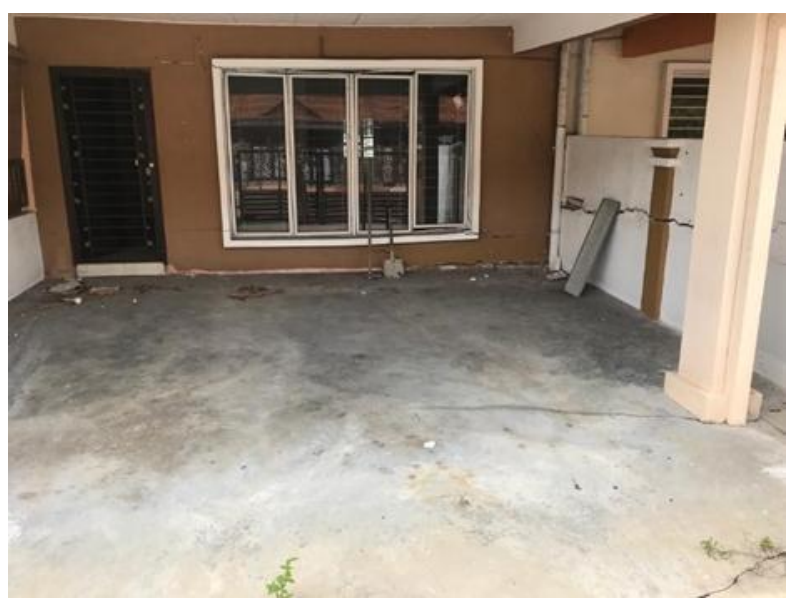

Figure 6. Structural damages with visible cracks were observed in front of house under study with structural and non-structural components.

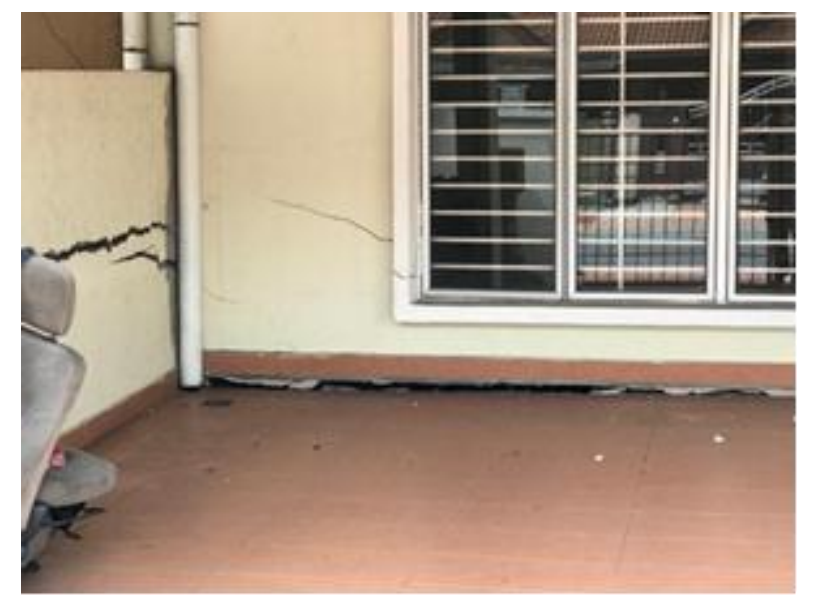

Figure 7. Neighboring house was experienced visible deflection of the floor ground slab and cracks on wall due to soil settlement.

Based on the interview session with the owner of the house, this house was not occupy by tenants as the owner seems to feel insecure and threatened due to rapid development of visible cracks as shown in Figure 6 and falling of concrete block from the wall. Moreover, there were also a lot of structural cracks occurred at bedrooms, hallways and staircase, kitchen and parking area located in front of the house as described below. Likewise, the neighboring houses were also observed to have the formation of visible structural cracks on the brick walls and severe soil settlement of the house's apron with noticeable deflection of floor slab as shown in Figure 7.

Figure 8(a) shows the layout out plan for ground floor of the investigated house together with coding numbers of cracks' marks in blue color. Meanwhile, Figure 8(b) shows the plan view for the first floor of the house together with a lot of cracks' marks on the wall at bedroom A, bedroom B and toilet. The locations of visible cracks in double-storey house were observed at Bedroom A, Bedroom B, Hallway and Staircase D, Kitchen D and Parking Area G. Table 2 shows the photographs of visible cracks and defects which were observed in these locations during visual inspection and categorized the crack width based on Table 1.

\subsection{Crack Width}

During inspection and monitoring the crack propagation, different types of cracks were detected at several locations of the house such as Bedroom A, Bedroom B, Hallway and Staircase D, Kitchen D, Parking and apron area D as clearly shown Table 2 . The types of propagated cracks include horizontal, vertical and diagonal directions with crack widths ranging from $0.3 \mathrm{~mm}$ up to $8 \mathrm{~mm}$ width. Table 3 shows the measurements of crack width at these locations for the duration of 3 months were taken on $18^{\text {th }}$ of July 2019 and $19^{\text {th }}$ October 2019. The labels and location of cracks were referred to Figure 7. According to Table 3, the results clearly showed that there are some differences of crack width at every location inspected on both dates. Based on both visual observations, there are active cracks start to move and propagate on the brick walls, columns and beams in this house and continuing until now. Furthermore, active cracks can lead to serious structural problems and they need special attention to repair and retrofit before hazardous and harmful accidents occur. According to Rajabather [16], the cracks in the buildings are a universal problem which faced throughout the world. Building components develop cracks whenever stress in the components exceeds its maximum capacity strength. Stress in the building components could be caused by externally applied forces such as dead, live, wind, seismic loads or foundation settlement or could be induced by internal due to temperature variations, moisture changes and chemical actions [18]. Cracks affect the building's artistic look and it destroys the wall integrity, as well as affecting the safety of structure and even reduces the durability of structure. 


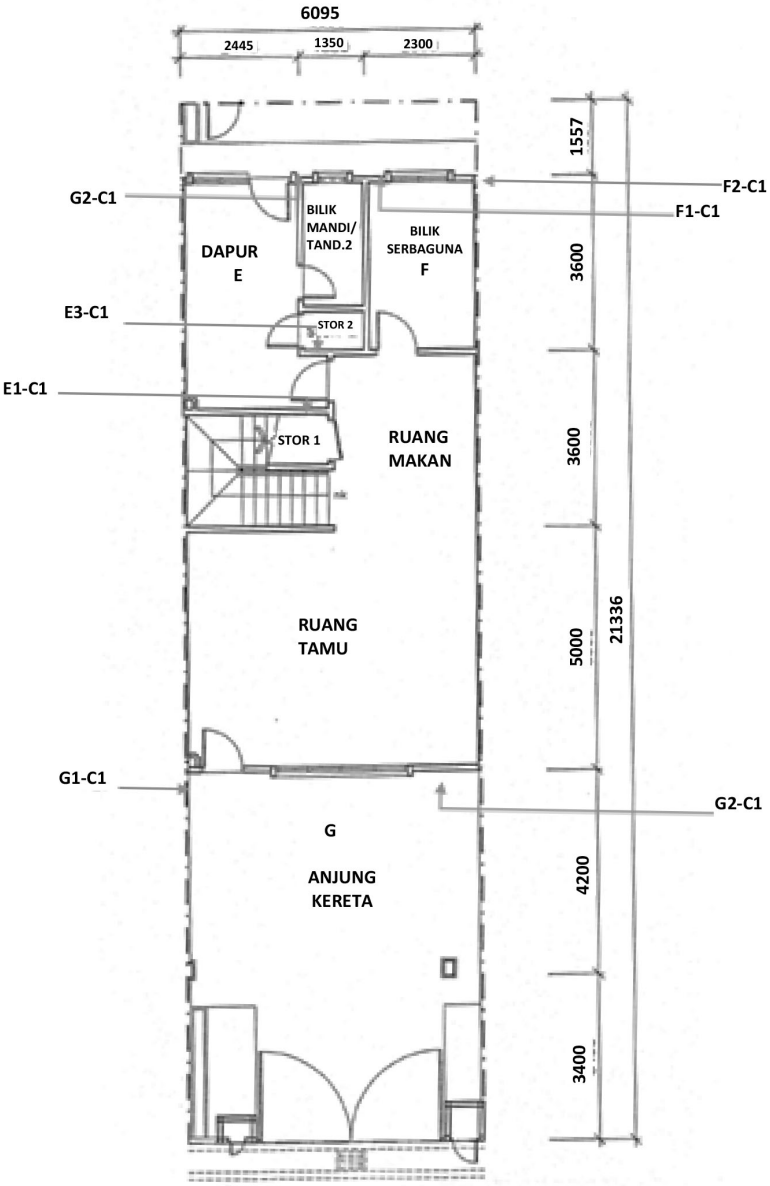

(a)

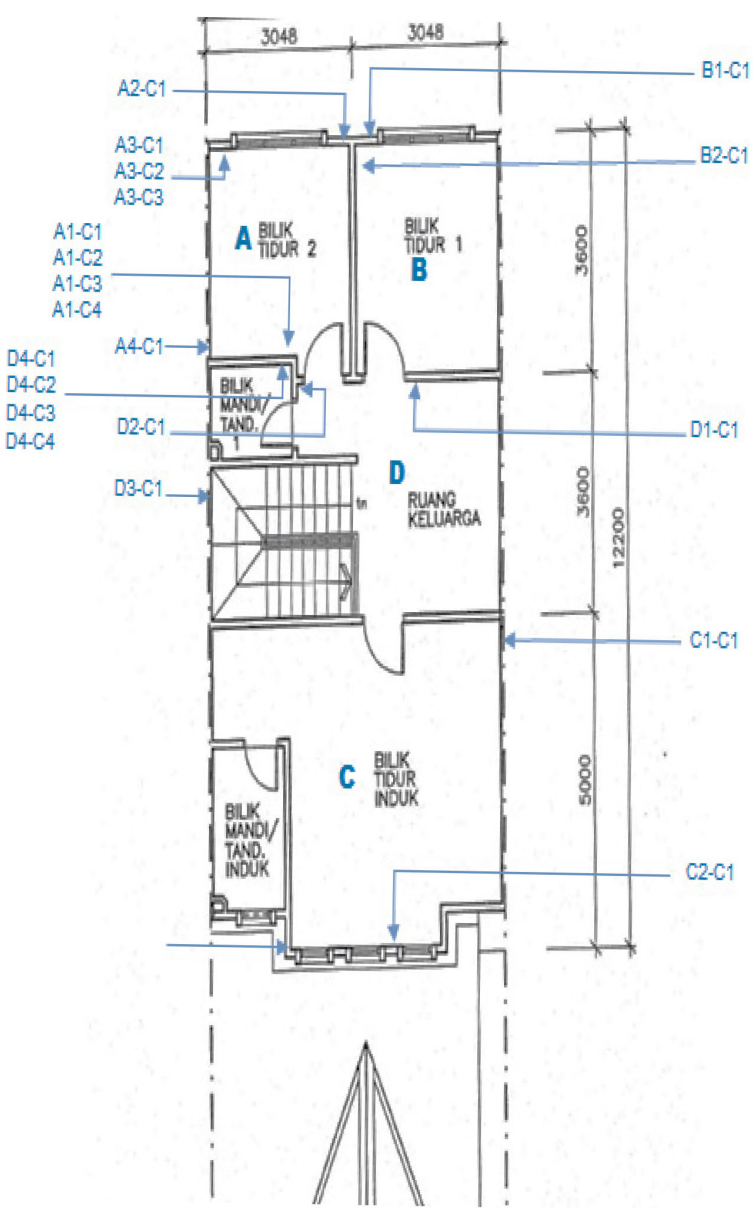

(b)

Figure 8. Layout plan of the case study house (a) Ground Floor (b) First Floor

Table 2. Visual observation and crack categorization during inspection of the damaged house

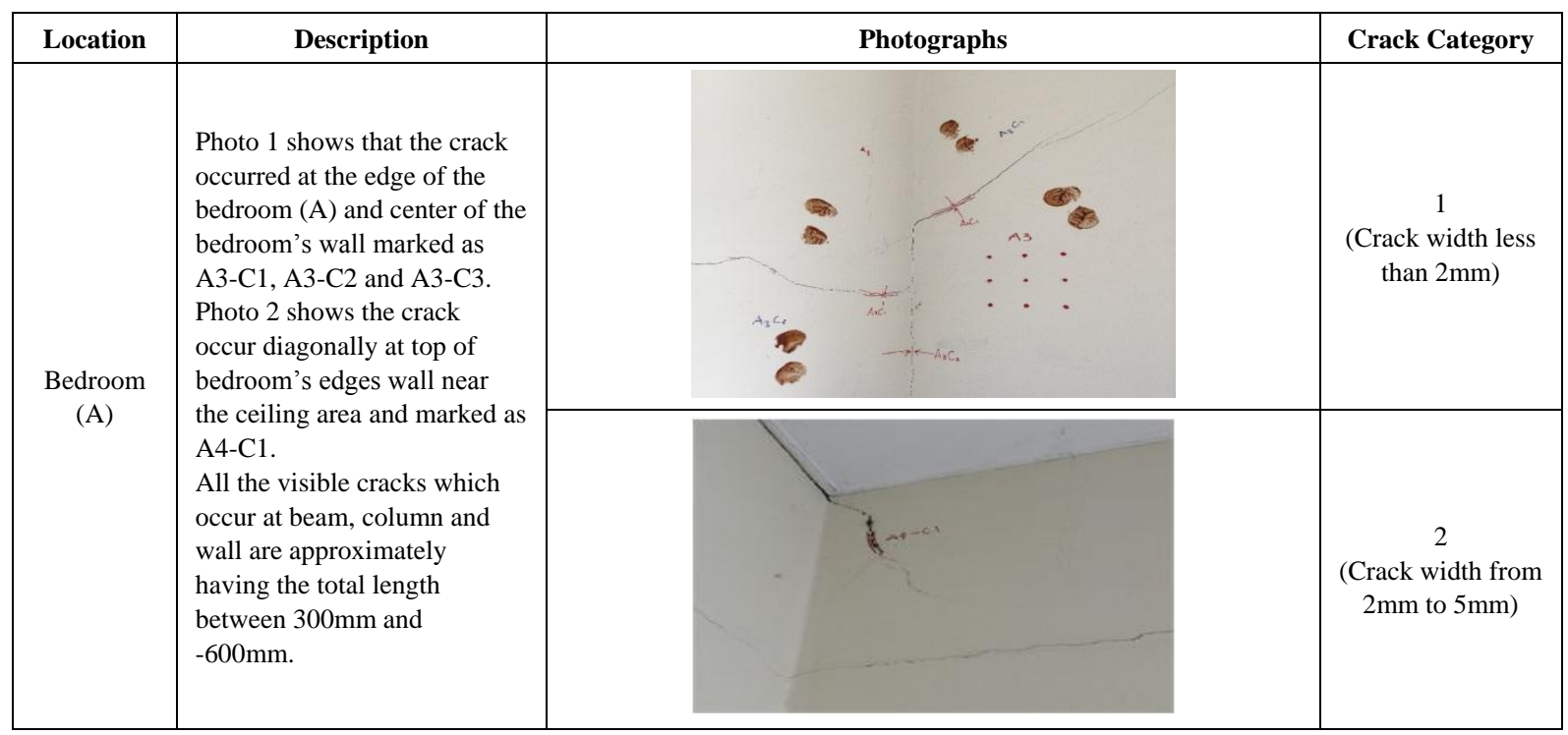




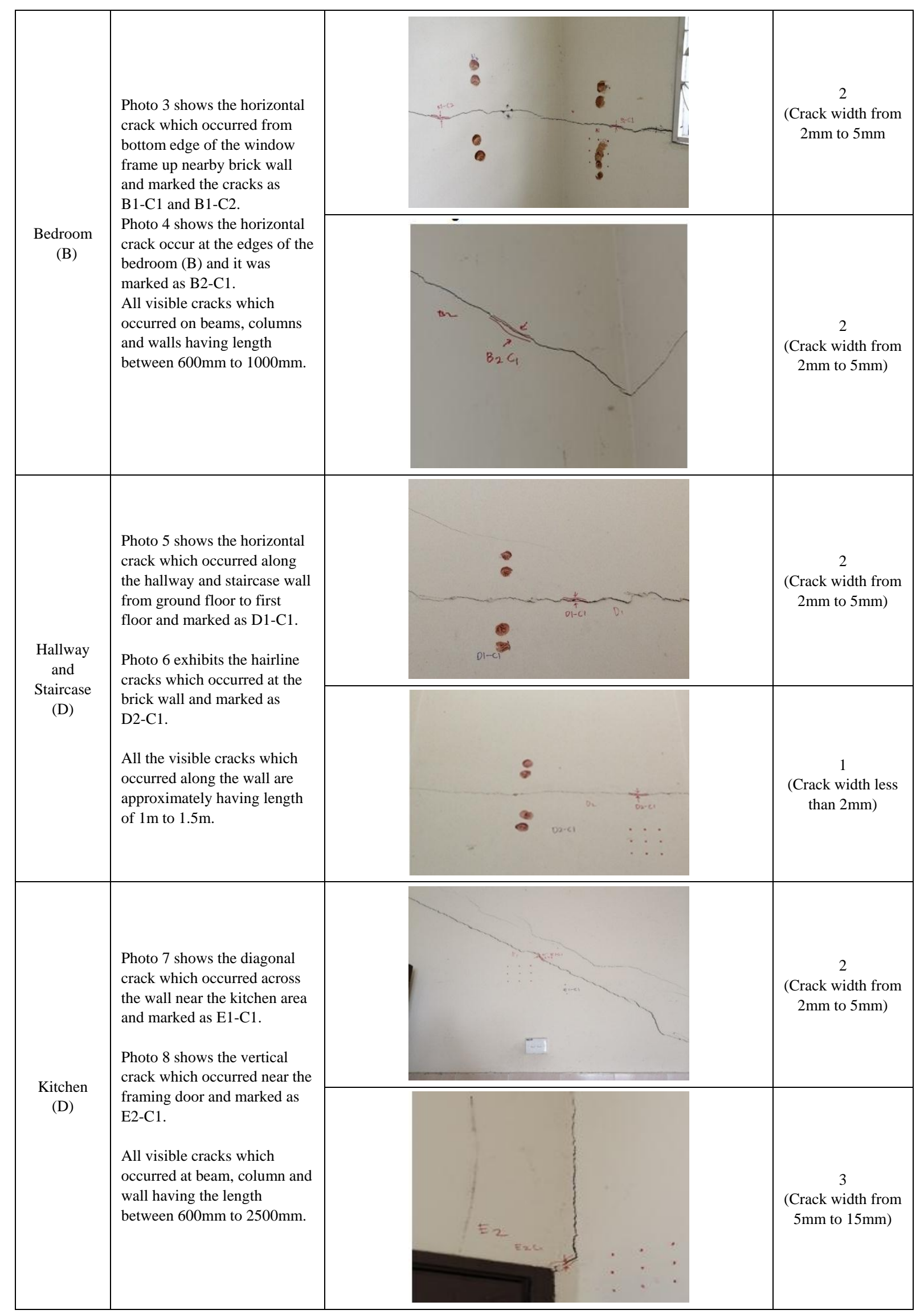


Table 3. Difference of Crack Width within 3 months duration

\begin{tabular}{|c|c|c|}
\hline \multirow{2}{*}{ No. } & Grid & $\begin{array}{c}\text { Crack Width } \\
\text { Difference (mm) }\end{array}$ \\
\cline { 2 - 3 } & \multicolumn{2}{|c|}{ Bedroom (A) } \\
\hline 1 & A1-C1 & 0.96 \\
\hline 2 & A1-C2 & 0.32 \\
\hline 3 & A1-C3 & 0.03 \\
\hline 4 & A1-C4 & 1.43 \\
\hline 5 & A2-C1 & 0.13 \\
\hline \multicolumn{3}{|c|}{ Bedroom (B) } \\
\hline 6 & B1-C1 & 0.31 \\
\hline 7 & B1-C2 & 0.04 \\
\hline 8 & B2-C1 & 0.13 \\
\hline \multicolumn{3}{|c|}{ Hallway and staircase } \\
\hline 9 & D1-C1 & 0.01 \\
\hline 10 & D2-C1 & 0.02 \\
\hline \multicolumn{2}{|c|}{ Parking Area } \\
\hline 11 & E1-C1 & 0.06 \\
\hline 12 & E2-C1 & 0.2 \\
\hline 13 & \multicolumn{2}{|c|}{} \\
\hline
\end{tabular}

Active cracks in concrete can be defined as live cracks which expand in length, width, and depth over time. It is difficult to repair the active cracks because these cracks continue to develop with time. Table 3 shows the differences in crack width measurement observed at specific locations of the building for three months. The selected locations of cracks width differences were visible possess an increase in development of crack width ranging from $0.01 \mathrm{~mm}$ to $1.00 \mathrm{~mm}$ within 3 months duration. The main bedroom in the house which located at the second floor has the most increment of cracks width with difference up to $1.43 \mathrm{~mm}$ in 3 months. Besides that, cracks were found at the hallway and staircase with the lowest crack width difference up to $0.01 \mathrm{~mm}$ difference. Overall, the results clearly indicated that all the cracks are categorized as an active crack where the width of crack experience extension within the 3 months duration. Therefore, it is important to find the root problems which cause these active cracks on the walls and columns. It is believed that these active cracks are due to soil settlement and existing of cavities underneath the house. Electrical resistivity test was conducted to trace the existing of the voids and to validate the results, a hole was dug as explained in other section.

\subsection{Ultrasonic Pulse Velocity (UPV)}

Ultrasonic pulse velocity test is mainly used to evaluate the concrete quality in structure by using the apparatus that transmit and receive transducer as shown in Figure 2. The UPV test was conducted by placing transmit and receive transducer between the crack and the measurements were taken at 13 grid locations of cracks. Table 4 shows the values of pulse velocity in $\mathrm{km} / \mathrm{s}$ with respect to the grading of concrete quality. There are four types of grading concrete quality mainly excellent, good, medium and poor [19].

Table 4. Concrete quality based on pulse velocity [19]

\begin{tabular}{|c|c|}
\hline Pulse Velocity $(\mathrm{km} / \mathrm{s})$ & Concrete Quality (Grading) \\
\hline Above 4.5 & Excellent \\
$3.5-4.5$ & Good \\
$3.0-3.5$ & Medium \\
Below 3.0 & Poor \\
\hline
\end{tabular}

Table 5. The difference values of UPV during monitoring process

\begin{tabular}{|c|c|c|c|c|c|}
\hline \multirow{3}{*}{ No } & Grid & \multicolumn{4}{|c|}{$\begin{array}{c}\text { Ultra Pulse Velocity } \\
(\mathrm{km} / \mathrm{sec})\end{array}$} \\
\hline & \multirow[b]{2}{*}{ Location } & Inspect & \multicolumn{3}{|c|}{ Monitored } \\
\hline & & $\begin{array}{c}18 \text { July } \\
2019 \\
\end{array}$ & \multicolumn{3}{|c|}{19 October 2019} \\
\hline \multicolumn{6}{|c|}{ Bedroom (A) } \\
\hline & & $200 \mathrm{~mm}$ & $300 \mathrm{~mm}$ & $200 \mathrm{~mm}$ & $300 \mathrm{~mm}$ \\
\hline 1 & $\mathrm{~A} 1-\mathrm{C} 1$ & 1.22 & 1.19 & 1.19 & 1.05 \\
\hline 2 & $\mathrm{~A} 1-\mathrm{C} 2$ & 1.40 & 1.67 & 1.22 & 1.43 \\
\hline 3 & A1-C3 & 0.64 & 0.77 & 0.58 & 0.65 \\
\hline 4 & A1-C4 & 0.65 & 0.70 & 0.55 & 0.62 \\
\hline 5 & $\mathrm{~A} 2-\mathrm{C} 1$ & 1.27 & 1.25 & 1.18 & 1.10 \\
\hline \multicolumn{6}{|c|}{ Bedroom (B) } \\
\hline 6 & $\mathrm{~B} 1-\mathrm{C} 1$ & 0.71 & 0.79 & 0.59 & 0.62 \\
\hline 7 & B1-C2 & 0.74 & 0.92 & 0.65 & 0.80 \\
\hline 8 & $\mathrm{~B} 2-\mathrm{C} 1$ & 0.69 & 0.93 & 0.54 & 0.88 \\
\hline \multicolumn{6}{|c|}{ Hallway and staircase } \\
\hline 9 & D1-C1 & 1.92 & 1.76 & 1.88 & 1.62 \\
\hline 10 & $\mathrm{D} 2-\mathrm{C} 1$ & 0.56 & 0.59 & 0.45 & 0.52 \\
\hline \multicolumn{6}{|c|}{ Kitchen } \\
\hline 11 & E1-C1 & 0.78 & 1.12 & 0.72 & 1.05 \\
\hline 12 & $\mathrm{E} 2-\mathrm{C} 1$ & 0.45 & 0.50 & 0.37 & 0.47 \\
\hline \multicolumn{6}{|c|}{ Parking Area } \\
\hline 13 & G1-C1 & 0.43 & 0.38 & 0.39 & 0.32 \\
\hline
\end{tabular}

In order to determine the quality of concrete for this house, the first and second reading of UPV tests were taken at 13 locations of cracks as specified in this study. Table 5 shows the two sets of reading of UPV which were taken on $18^{\text {th }}$ of July 2019 and $19^{\text {th }}$ of July 2019. The overall results show that the pulse velocity values were decreasing when comparing between first reading and second reading. By comparing these values of pulse velocity in Table 5 and Table 4, most of the velocity 
values are below $3.0 \mathrm{~km} / \mathrm{s}$ and it can be classified that the quality of concrete is poor for all 13 locations of cracks. Thus, it can be concluded that there is possibility that the cracks could contribute to the deterioration and concrete structures quality using UPV test. Table 5 also shows that the mean ultrasonic pulse velocity taking at the cracks of beams at hallway and staircase area is $1.92 \mathrm{~km} / \mathrm{s}$ and the highest result as compared to other values. In addition, the lowest UPV value is $0.32 \mathrm{~km} / \mathrm{s}$ which located at the parking area garage. Yet, these two values are still below $3.0 \mathrm{~km} / \mathrm{s}$ and can be categorized as poor quality of concrete. There is a linear relationship between compressive strength of concrete and values of UPV [24].Thus, it can be concluded that the qualities of concrete at 13 locations of cracks were categorized as poor quality which require repair, strengthening and retrofitting actions. It is suggested to use sealant and epoxy resin injection to repair the existed cracked on the wall and floor slab.

\subsection{Compressive Strength of Concrete Using Rebound Hammer Test}

Table 6. Comparison of compressive strength within 3 months of inspection and monitoring

\begin{tabular}{|c|c|c|c|}
\hline \multirow{3}{*}{ No. } & Grid & \multicolumn{2}{|c|}{ Compressive Strength of Concrete (MPa) } \\
\hline & \multirow{2}{*}{ Location } & Inspection & Monitored \\
\hline & & 18 July 2019 & 19 October 2019 \\
\hline \multicolumn{4}{|c|}{ Bedroom (A) } \\
\hline 1 & $\mathrm{~A} 1-\mathrm{C} 1$ & 34 & 29 \\
\hline 2 & $\mathrm{~A} 1-\mathrm{C} 2$ & 34 & 29 \\
\hline 3 & A1-C3 & 34 & 29 \\
\hline 4 & A1-C4 & 34 & 29 \\
\hline 5 & $\mathrm{~A} 2-\mathrm{C} 1$ & 30 & 27 \\
\hline \multicolumn{4}{|c|}{ Bedroom (B) } \\
\hline 6 & $\mathrm{~B} 1-\mathrm{C} 1$ & 27 & 26 \\
\hline 7 & $\mathrm{~B} 1-\mathrm{C} 2$ & 27 & 26 \\
\hline 8 & B2-C1 & 30 & 29 \\
\hline \multicolumn{4}{|c|}{ Hallway and staircase } \\
\hline 9 & D1-C1 & 29 & 27 \\
\hline 10 & D2-C1 & 30 & 20 \\
\hline \multicolumn{4}{|c|}{ Kitchen } \\
\hline 11 & E1-C1 & 26 & 25 \\
\hline 12 & E2-C1 & 26 & 25 \\
\hline \multicolumn{4}{|c|}{ Parking Area } \\
\hline 13 & G1-C1 & 26 & 24 \\
\hline
\end{tabular}

Rebound hammer is the non-destructive testing apparatus which used to determine the compressive strength of on-site concrete and estimated its strength using calibrated strength curves. The rebound hammer method provides a convenient and rapid indication of the compressive strength of concrete by means of establishing a suitable correlation between the rebound index and the compressive strength curves. The rebound hammer test was conducted closed to the 13 locations of cracks at ground floor and first floor of the house as shown in Figure 6 . The data collection of rebound hammer test was made to determine the compressive strength of normal concrete on the walls, beams and columns where the cracks were visible. The first test was conducted on $18^{\text {th }}$ of July 2019 and the second test was commenced on $19^{\text {th }}$ of October 2019. Table 6 shows the value of inspection and monitored compressive strength of concrete at 13 marked locations of the house includes 5 different spots. The average in-situ characteristic compressive strength of concrete is decreased from $34 \mathrm{MPa}$ to $29 \mathrm{MPa}$ at Bedroom A. Bedroom B also indicates that the compressive strength of the concrete has decreased from $27 \mathrm{MPa}$ to $26 \mathrm{MPa}$ as it is influenced by the condition such that the particular member has internal micro cracking, flaws and heterogeneity across the cross-section. It can be seen and concluded that this house has undergo tremendous losses of compressive strength ranging from $1 \mathrm{MPa}$ to $10 \mathrm{MPa}$ within 3 months during inspection and monitoring process.

\subsection{Result of Resistivity Test and Soil Profiling}

Based on visual inspection and monitored assessment conducted two times within 3 months, there are three main problem encountered to the structural cracks, low quality of concrete and decreasing of compressive strength of concrete. These problems cause soil settlement with low bearing capacity and cavities of soils by changing of ground water table level. The cavities in the soils were notified based on the resistivity test conducted on $23^{\text {rd }}$ of July 2019 using ABEM Terrameter LS2 and 200m cable as shown in Figure 4. Two resistivity tests were conducted with Line 1 of $40 \mathrm{~m}$ inside the house and Line 2 with $60 \mathrm{~m}$ in front of the house and these lines are perpendicular to each other. The systematic arrangement of ABEM Terrameter LS2, steel electrode and jumper cable is shown in Figure 5. After analyzing the data from resistivity test using Res2DINV software, the soil profiles were plotted for Line 1 and Line 2. Figure 10 shows the soil profile for Line 1 with $10 \mathrm{~m}$ depth and $40 \mathrm{~m}$ length. Meanwhile, Figure 11 shows the soil profile for Line 2 with $20 \mathrm{~m}$ depth and $60 \mathrm{~m}$ length. Different colors of contour lines in Figure 10 and 11 show different resistivity and conductivities of igneous metamorphic rocks, sedimentary rocks, soils and water. The interpretation of the contour lines and colors is based on resistivity index and conductivity for materials inside the soil. Table 7 shows the resistivity index and conductivity for some common rocks, minerals and chemicals [20, 21, 22]. Based on Table 7, the predicted subsurface of Line 1 is dominantly underlain by very low resistivity value where the value less than 40 ohm.m with bluish color 
which is interpreted as saturated zone or water filled area. For value of resistivity less than $40 \mathrm{ohm} . \mathrm{m}$ indicates that this area consists of wet material such as water with conductive solution such as leachate. Similarly, the subsurface of Line 2 is underlain by very low resistivity value with values less than $30 \mathrm{ohm} . \mathrm{m}$ ( $<30 \mathrm{ohm} . \mathrm{m})$ at the center of the line which is interpreted as saturated zone or water filled area. This value indicates that this area filled with water that becomes saturated. Therefore, it is suspected that the underground condition of this line consist of water that filled the voids. In order to validate that there was water and cavity based on the electrical resistivity test and to determine the type of soil underneath the house, a hole was excavated using hoe at the car porch area as marked with dark arrow as shown in Figure 10. After digging the hole at this location until depth of $800 \mathrm{~mm}$, groundwater level was discovered at the car porch area as shown in Figure 9. There were several spring water holes coming out from ground beam which located underneath the house. This soil consists of clay, sand and limestone. A layer of clay which is located underneath the house kept the ground water level close to the surface of the soil. Clay has a small particle size less than 2 micrometer which can hold the water above it. Water molecules are strongly attracted to clay mineral surfaces and can distribute itself evenly throughout the water. The predominant clay mineral which has high swelling stress and soil suction can hold the water together [25]. Furthermore, it is believed that this housing area was a dumping site originally from a small stream before constructing this house. Moreover, lacking of proper soil investigation prior to the construction of houses also can lead to failure in selecting a suitable type of foundation which causes the settlement of buildings and houses [17]. Therefore, it is recommended that the cement-based grout to fill the cavities and underpinning with a solid foundation lay below ground level to support or strengthen the house.

Moreover, high level of groundwater table also can jeopardize the strength of the soil and causing the foundation to constantly be in partial submerged condition with water during its service life. There are several symptoms of foundation and soil failure that were found in this case study which are doors and windows not being closed properly or sticking, diagonal cracks in the interior and exterior wall, cracks and splitting on tiles and ground floor as shown in Figure 12 and 13. This phenomenon will cause the overall structure to settle and has a tendency to be tilted. However, it was found through the non-destructive assessment that the existing structure is in distress condition in which the concrete performance due to quality and compressive strength are poor at most locations of this house. Structural damage of the building becomes more severe where the progressive cracks on non-structural (wall and floor) and structural (columns and beam) elements were developed in a short-time period.

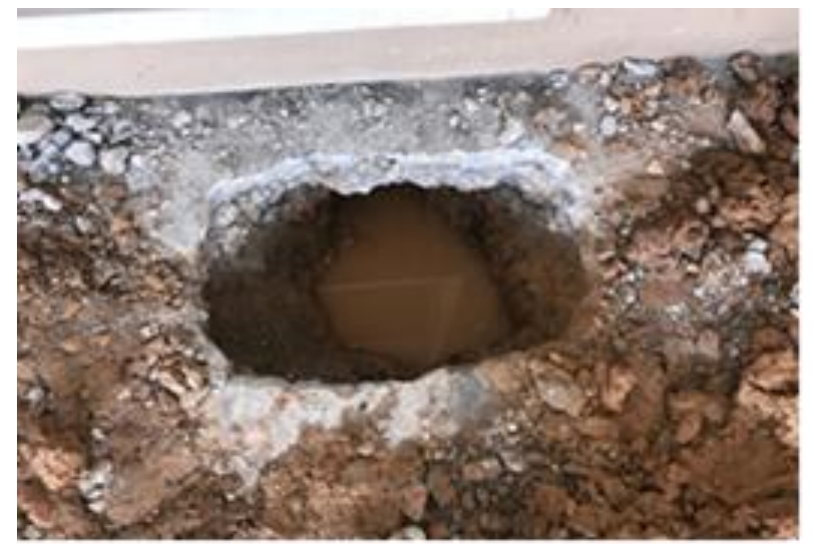

Figure 9. Ground Water Table at $800 \mathrm{~mm}$ Depth

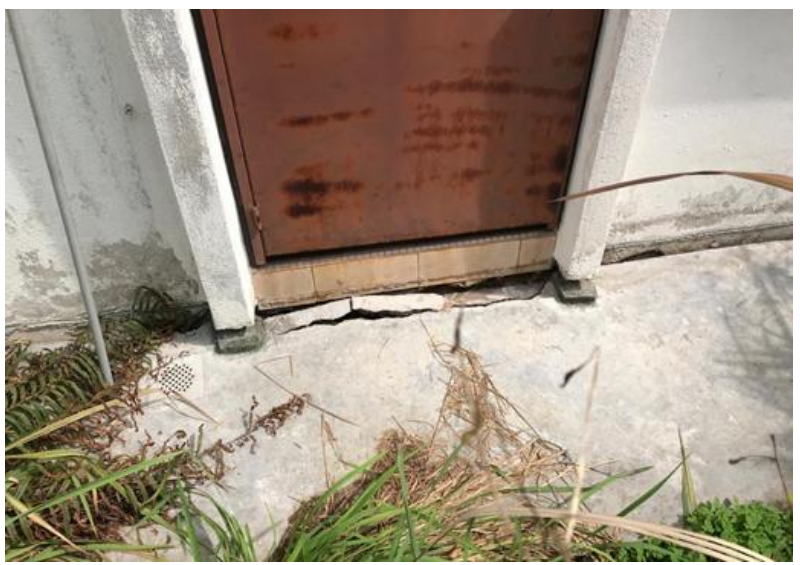

Figure 12. Splitting between ground floor and wall

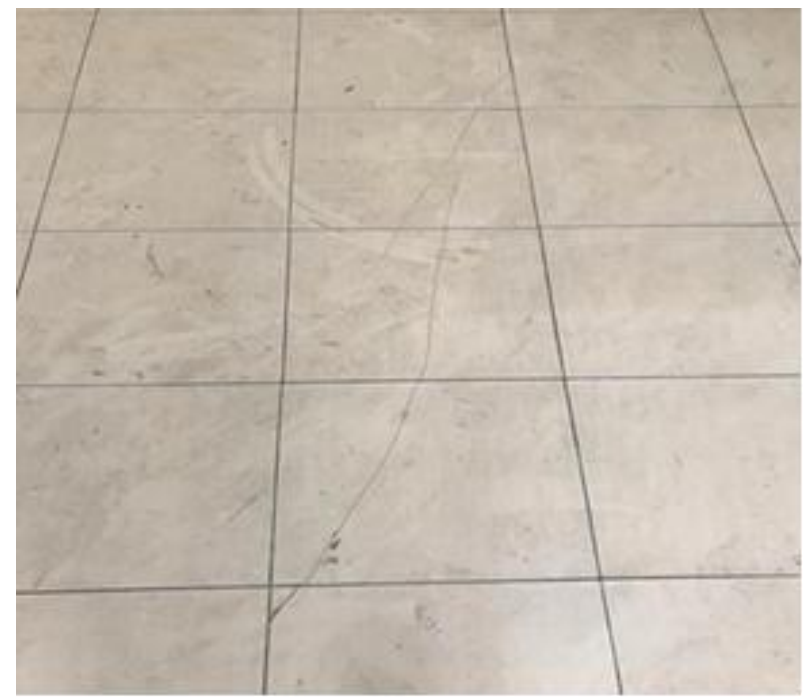

Figure 13. Cracking on the tile and floor 
Line 1

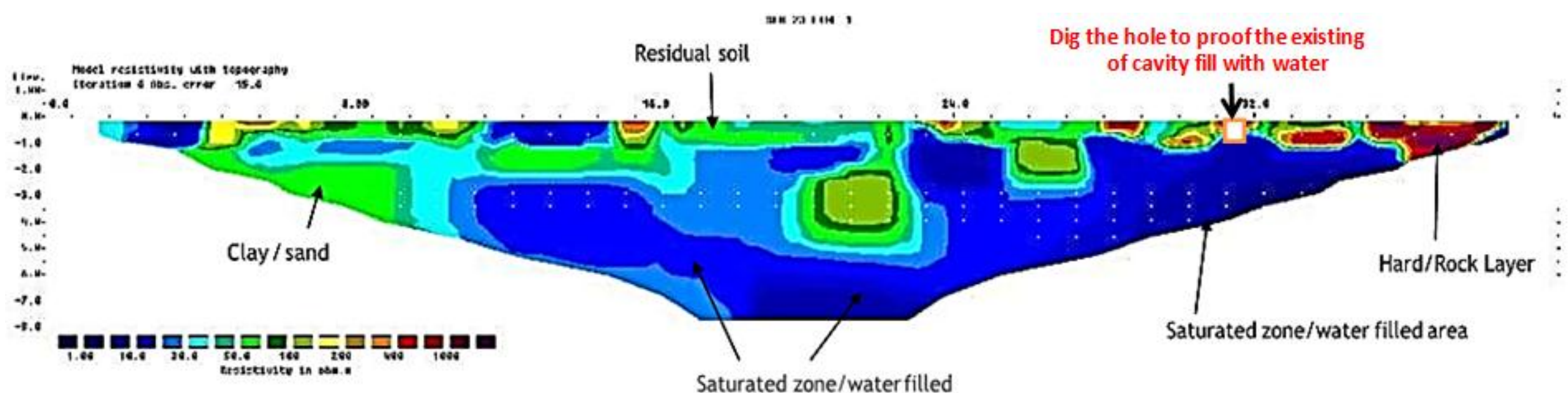

Figure 10. Inverse model for resistivity image of Line 1 with $40 \mathrm{~m}$ length inside the house at ground floor level

Line 2

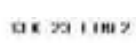

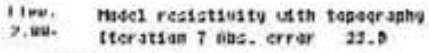

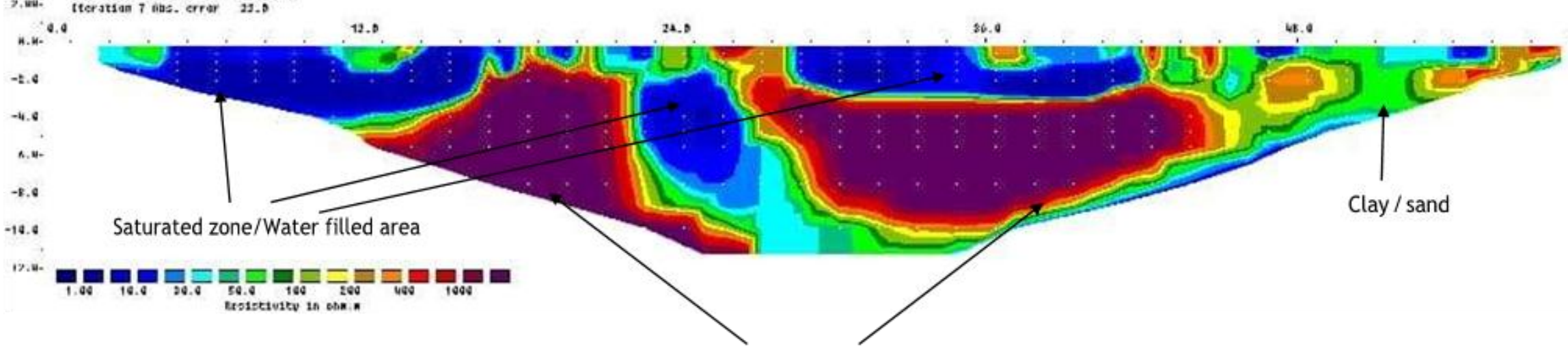

Figure 11. Inverse model for resistivity image of Line 2 with $60 \mathrm{~m}$ length in front the house 
Table 7. Resistivity index of some common rocks, minerals and chemicals $[20,21,22]$

\begin{tabular}{|c|c|c|}
\hline Material & Resistivity $(\Omega \mathrm{m})$ & Conductivity (Siemen/m) \\
\hline \multicolumn{3}{|c|}{ Igneous and Metamorphic Rocks } \\
\hline Granite & $5 \times 10^{3}-10^{6}$ & $10^{-6}-2 \times 10^{-4}$ \\
\hline Basalt & $10^{3}-10^{6}$ & $10^{-6}-10^{-3}$ \\
\hline Slate & $6 \times 10^{2}-4 \times 10^{7}$ & $2.5 \times 10^{-8}-1.7 \times 10^{-3}$ \\
\hline Marble & $10^{2}-2.5 \times 10^{8}$ & $4 \times 10^{-9}-10^{-2}$ \\
\hline Quarzite & $10^{2}-2 \times 10^{8}$ & $5 \times 10^{-9}-10^{-2}$ \\
\hline Schist & $50-10^{4}$ & $2 \times 10^{-2}-10^{-4}$ \\
\hline Hornfels & $8 \times 10^{3}-6 \times 10^{7}$ & $1.7 \times 10^{-8}-1.3 \times 10^{-4}$ \\
\hline \multicolumn{3}{|c|}{ Sedimentary rocks } \\
\hline Sandstone & $8-4 \times 10^{3}$ & $2.5 \times 10^{-4}-0.125$ \\
\hline Shale & $20-2 \times 10^{3}$ & $5 \times 10^{-4}-0.05$ \\
\hline Limestone & $50-4 \times 10^{2}$ & $2.5 \times 10^{-3}-0.02$ \\
\hline \multicolumn{3}{|c|}{ Soils and water } \\
\hline Clay & $1-100$ & $0.01-1$ \\
\hline Alluvium & $10-800$ & $1.25 \times 10-3-0.1$ \\
\hline Groundwater (Fresh) & $10-100$ & $0.01-0.1$ \\
\hline Seawater & 0.2 & 5 \\
\hline
\end{tabular}

\section{Conclusions}

Based on the data collected, analysis and interpretation of site results of a double-storey house which suffered severe cracks on the walls and floor slabs, the following conclusions can be drawn as follows:

1) The visual damage inspection and non-destructive test (NDT) indicate that structural damage of the house can be categorized as moderate damage which can be repaired and retrofitted after inspections. The results of rebound hammer and Ultrasonic Pulse Velocity (UPV) during the monitoring works show that the compressive strength of concrete was decreasing with time and contribute to poor quality of concrete.

2) The monitoring period of crack width within 3 months interval exhibits that these types of cracks are active where the cracks are continuing to propagate until serious accident will occur in the future such as partial of full collapse of the house.

3) The type of defect or damage found in the walls and floor slabs was the progressive crack which propagated at 13 locations of non-structural and structural member. It is also resulted in the soil settlement due to low bearing capacity soil caused by high level of groundwater table.

4) From the electrical resistivity survey, it shows that there are some cavities filled with water underneath the double-storey house and proof by excavating a hole at the marked place as shown in Figure 10.

5) The types of soil underneath the house are clay, sand and limestone which were discovered after digging the hole in front of the car porch area based on the resistivity test as shown in Figure 9.

6) It is recommended that the cement-based grout can be used to fill these cavities and underpinning with a solid foundation laid below ground level to support or strengthen the house before repair the cracks using sealant and epoxy resin.

\section{Acknowledgements}

Special thank goes to Malaysian of Higher Education of Malaysia (MOHE), Putrajaya, Malaysia who fund this research work under Fundamental Research Grants with file No: 600-RMI/FRGS 5/3 (0091/2016) and RMI (Research Management Institute) for managing this research work in the most efficient ways. Gratitude and appreciation to the laboratory staff members for their invaluable assistance during the course of this experimental research work.

\section{REFERENCES}

[1] R. Shinde and K. Meshram, Investigation of Building Failure Using Structural Forensic Engineering, 2020, International Journal of Scientific \& Technology Research Volume 9, Issue 04, 2020, ISSN 2277-8616.

[2] N. A. Spanos, J. S. Sakellariou and S. D, Fassois, Vibration-response-only Statistical Time Series Structural Health Monitoring Methods: A Comprehensive Assessment via A Scale Jacket Structure, 2020, Structural Health Monitoring, Volume 19, Issue 3, pp 736-750

[3] N.H. Hamid, and S.A. Anuar, Seismic Risk Assessment of Three Types of Exterior Beam-column Joints Using Fragility Curve, Risk Analysis Journal, Volume 9, pg 95.

[4] N.M. Mohamad, N.H. Hamid, S.H. Ghani and Z.A Hamid, Seismic Behaviour of Precast Shear Key Wall Under In-plane Lateral Cyclic Loading, 2014, Malaysian Construction Research Journal, Volume 15, Issue 2, pp 63-73

[5] N.H. Hamid, M. I. Adiyanto and M. Mohamad, Seismic Performance Of Single-Bay Two-Storey RC Frame Under In-Plane Lateral Cyclic Loading, 2017, ARPN Journal of Engineering and Applied Sciences, Volume 12, Issue 22, pp 6502-6510.

[6] N.H. Hamid, S.A Anuar, H. Awang and M.E. Kori, Experimental study on seismic behavior of repaired tunnel form building under cyclic loading, 2018, Asian Journal of Civil Engineering, Volume 19, Issue 3, pp 343-354

[7] G. H. Yunusa, U. Hamza, A.Y. Abdulfatah, and A. Suleiman, Geotechnical Investigation into The Causes of Cracks in Building: A Case Study, 2013, Electronic Journal of Geotechnical Engineering, Vol. 18, pp 2823-2833.

[8] K. Kunal and N. Killemsetty, Study on Control of Cracks 
in Structure through Visual Identification and Inspection, 2014, IOSR Journal of Mechanical and Civil Engineering, Volume 11, Issue 5, pp 64-72, ISSN No: 2320-334X

[9] N. Jamaluddin, D. Yeoh, A.H. Ghani, K. H. Boon, S.S. Ayob, M.H. Ibrahim, N. Mohamad, T.N. Chik, N.H Ghafar, A Case Study of Residential Buildings Subjected to Cracking Failures, 2018, International Journal of Integrated Engineering, Special Issue 2018: Civil \& Environmental Engineering, Vol. 10 No. 2, pp. 118-122.

[10] T. Godlewski, W. Bogusz and L. Kaczyński, Change In Groundwater Conditions As A Cause Of Structural Failure - Selected Case Studies, 2019, MATEC Web of Conferences 284, (2019) https://doi.org/10.1051/matecconf /20192840.

[11] B.K. Koay, M.F. Ishak, M.S.I. Zaini, and M.F. Zolkepli, Investigation and Monitoring of Groundwater Level: Building Crack Near to IIUM Kuantan, (2018) International Journal Of Engineering Technology And Sciences (IJETS), ISSN: 2462-1269 Vol.5 (3), pp 51-56.

[12] Ohio Department of Transportation and U.S. Department of Transportation Federal Highway Administration, 2002, Water-Resources Investigations Report 02-4041.

[13] E. Cardarelli, G. Di Filippo and E. Tuccinardi, Electrical Resistivity Tomography To Detect Buried Cavities In Rome: A Case Study, 2006, Journal of Near Surface Geophysics, pp 387-392.

[14] M. Farooq, S. Park, Y.S. Song, J.H. Kim, M. Tariq and A. A. Abraham, Subsurface Cavity Detection In A Karst Environment Using Electrical Resistivity (Er): Earth Science Research Journal, Vol. 16, No.1, ISSN: 1794-6190

[15] M. Lech, Z. Skutnik, M. Bajda and K. Markowska-Lech, Applications of Electrical Resistivity Surveys in Solving Selected Geotechnical and Environmental Problems, 2020, Applied Sciences Journal, MDPI, Volume 10, Issue 7, ISSN No: 2076-3417.

[16] A. Rajabather, Investigation of Cracks in Buildings, 2017, Conference on Forensic Structural Engineering at VIT University, Chennai Campus, India.

[17] J.B. Burland, B.B. Broms, and V.F.B DeMello, Behaviour of Foundations and Structures: State-of-the Art Report." Proceedings of the Ninth International Conference on Soil Mechanics and Foundation Engineering, 1977, Japanese Geotechnical Society, Tokyo, vol. 2, pp. 495-546.

[18] Y. S. Masurkar, A. C. Attar, Investigating the Causes for Failures in Construction by Taking a Case Study, 2014, Current Trends in Technology and Science ISSN: 22790535. Volume: 3, Issue:5 pp 24-36.

[19] T. Gehlot, S.S. Sankhla, S.S. Gehlot and Akash Gupta, Study of Concrete Quality Assessment of Structural Elements Using Ultrasonic Pulse Velocity Test, 2016, Journal of Mechanical and Civil Engineering Volume 13, Issue 5, pp 15-22.

[20] G.V. Keller, and F.C. Frischknech., (1996). Electrical Method In Geophysics Prospecting. Pergamon Press. Inc., Oxford. p. 517.

[21] F. Daniels, and R.A. Alberty, (1996). Physical Chemistry. John Wiley and Sons, Inc. Dey A. and Morrison H.F., 1979. Resistivity modelling for arbitrarily shaped two-dimensional structures. Geophysical Prospecting Volume 27, Issue 1, pp 106-136.

[22] M.H. Loke, and R.D., Barker, 1996. Practical techniques for 3D resistivity surveys and data inversion. Geophysical Prospecting Volume 44, Number 3, pp 499-523. GPPRAR44(3)351-554(1996), ISSN 0016-8025.

[23] Aziman Madun, Saiful Azhar Ahmad Tajudin, Mohd Zainizan Sahdan, Mohd Firdaus Md Dan @ Azlan and Mohd Khaidir Abu Talib, Electrical resistivity and induced polarization techniques for groundwater exploration, 2018, International Journal of Integrated Engineering, Vol. 10 No. 8, pp 56-60.

[24] M. A. Chandak and P.Y. Pawade. Compressive Strength and Ultrasonic Pulse Velocity of Concrete with Metakaolin, 2020, Civil Engineering and Architecture 8(6): pp 1277-1282. DOI: 10.13189/cea.2020.080611

[25] A. A. Fondjo and T. C. Dzogbewu. Swelling Stress and Suction Correlation of Compacted, Heaving Soils, 2020, Civil Engineering and Architecture 8(4): pp 721-733. DOI: 10.13189/cea.2020.080434 